\title{
Cross-cultural adaptation to Brazilian Portuguese of the Waterloo Footedness Questionnaire-Revised:WFQ-R-Brazil
}

\author{
Adaptação transcultural para o português brasileiro do Waterloo Footedness \\ Questionnaire-Revised:WFQ-R-Brasil
}

Monike Barros Camargos ${ }^{1,4}$, Andressa da Silva Palmeira ${ }^{1,4,6}$, Emerson Fachin-Martins ${ }^{1,2,3,5}$

\begin{abstract}
Post-stroke hemiparesis causes compensated postures, which can modify the footedness established before the impairment. Recently, a paresis severity-modulated dominance hypothesis stated that measures to detect footedness become crucial to float new ideas for neurorehabilitation strategies. The Waterloo Footedness Questionnaire-Revised (WFQ-R) represents the most acceptable measure but it had not yet been cross-culturally adapted for Portuguese spoken in Brazil. Our aim was to cross-culturally adapt the WFQ-R to Brazilian Portuguese, verifying its reliability. We completed the essential steps to cross-culturally adapt one version, tested in 12 patients with post-stroke hemiparesis and 12 able-bodied individuals, sampled by convenience, to verify reliability. Measurements were taken by two independent raters during the test and by one of them at the one-week retest. No great semantic, linguistic or cultural differences were found, and acceptable reliability was recorded. The WFQ-R-Brazil is reliable and ready for use in the Brazilian able-bodied and post-stroke hemiparesis population.
\end{abstract}

Keywords: diagnosis; monitoring; hemiplegia.

\section{RESUMO}

Hemiparesia pós-doença cerebrovascular causa posturas compensadas que podem modificar predominância de uso do pé adotada antes da deficiência. Recentemente, hipótese de predominância modulada pela gravidade da paresia declara que medidas para detectar predominância tornaram-se cruciais para sugerir ideias em busca de estratégias de neurorreabilitação. A Waterloo Footedness Questionnaire-Revised (WFQ-R) representa a medida mais aceita e não foi ainda adaptada transculturalmente para o Português brasileiro. Nosso objetivo foi então adaptar o WFQ-R, verificando sua confiabilidade. Nós completamos os passos essenciais para adaptar uma versão testada em 12 pessoas com hemiparesia e 12 fisicamente aptas amostradas por conveniência para procedimentos de verificação da confiabilidade. Medidas foram tomadas por dois examinadores independentes durante o teste e por um deles no reteste após uma semana. Nenhuma diferença semântica, linguística ou cultural foi encontrada, e confiabilidade aceitável foi registrada. WFQ-R-Brasil é confiável e está pronto para uso na população de brasileiros fisicamente aptos e com hemiparesia.

Palavras-chave: diagnóstico; monitoramento; hemiplegia

Right or left brain asymmetries have been demonstrated in studies of complex cognitive functions such as musical abilities, language, emotions, and visuospatial tasks. ${ }^{1}$. Mutha et al. ${ }^{2}$ defended that a hemispheric specialization model, in which unilateral hemispheres become responsible through different motor control mechanisms, decreases the energy expenditure and time for communication between processing units (efficiency), optimizing performance. With this rationale, the asymmetry of performing different tasks by choosing a preferred hand or foot

${ }^{1}$ Universidade de Brasília, Faculdade de Ceilândia, Programa de Pós-Graduação em Ciências e Tecnologias em Saúde, Brasília DF, Brasil:

${ }^{2}$ Universidade de Brasília, Faculdade de Ceilândia, Programa de Pós-Graduação em Ciências da Reabilitação, Brasília DF, Brasil;

${ }^{3}$ Universidade de Brasília, Centro de Apoio ao Desenvolvimento Tecnológico, Programa de Pós-Graduação em Propriedade Intelectual e Transferência de Tecnologia para a Inovação, Brasília DF, Brasil;

${ }^{4}$ Secretaria do Estado de Saúde do Distrito Federal, Governo do Distrito Federal, Brasília DF, Brasil;

${ }^{5}$ Faculdade de Ceilândia, Departamento de Fisioterapia, Brasília DF, Brasil;

${ }^{6}$ Secretaria do Estado de Saúde do Distrito Federal, Programa de Residência Multiprofissional em Saúde, Brasília DF, Brasil.

Correspondence: Emerson Fachin-Martins; Campus de Ceilândia, Centro Metropolitano, Conjunto A, Lote 01, Brasília, Brazil; E-mail: efmartins@unb.br Support: Scholarship: Conselho Nacional de Desenvolvimento Científico e Tecnológico (CNPq), Processo: 310029/2014-7. Grant: Programa Pesquisador Visitante Especial (PVE) da Coordenação de Aperfeiçoamento de Pessoal de Nivel Superior (CAPES), Processo: 88881.068134/2014-01, Proposta:300665. Conflict of interest: There is no conflict of interest to declare.

Received 07 June 2017; Accepted 17 July 2017. 
could represent more than a smart way to justify the hemispheric specialization ${ }^{3}$.

Footedness has been considered more sensitive than handedness as a behavioral index of hemispheric lateralization in terms of emotional perception and language organization $^{4,5}$. Sadeghi et al. ${ }^{4}$ recommended consideration of the preferentially-used foot in performing a specific motor task as a strategy to identify footedness. Strategies to observe which foot is chosen to manipulate or move an object, when required to kick a ball, or to pick up a marble from the floor with the toes, could more precisely help identify the footedness. With this approach, the foot used to support the body weight would be considered the non-dominantly used ${ }^{3,45}$.

The Waterloo Footedness Questionnaire-Revised (WFQ-R), originally developed in English by Elias et al. ${ }^{5}$, is the most-used instrument to assess foot dominance. It is easy to apply but had not been translated and cross-culturally adapted for the Brazilian population ${ }^{5}$. Despite footedness having been related to functional asymmetries, studies considering the effects of footedness on gait and postural control for able-bodied people have presented divergent results, creating doubts about similarities or disparities coming from the preference referred to by performing tasks or performing weight support ${ }^{4,6}$.

Blaszczyk et al. ${ }^{6}$, for example, observed that seven of their 21 elderly participants evaluated had asymmetric distribution overloading the left lower limb that was not defining dominance. The authors considered that the lower limb less affected by the aging process would be responsible for maintaining stability ${ }^{7}$. However, Hesse et al. ${ }^{8}$ reported no significant correlation between the overloaded lower limb and the preferentially-used foot during the seated-to-standing movement in healthy youngsters 8 .

For post-stroke hemiparesis, the unaffected side could be considered the preferentially-used hemibody for performing tasks, establishing the idea labelled by Mundim et al. ${ }^{7}$ as a convenience hypothesis. The convenience hypothesis states that for chronic post-stroke hemiparesis, motor dominance may be modified for convenience, in other words, individuals learn to use the unaffected hemibody to perform daily activities, as well as overloading the unaffected lower limb in the orthostatic position ${ }^{7}$. This choice seems to reflect a strategy to overcome the motor and sensory deficits of the affected body. However, non-Pusher's syndrome asymmetries with overload on the affected side have also been identified as a motor strategy ${ }^{7,9}$.

Asymmetric strategies overloading both hemibodies bring to mind that factors such as severity of motor and sensory impairments and pushing behavior have been identified as being responsible for the asymmetric distribution with overload of the affected limb in chronic stroke survivors ${ }^{10}$, reinforcing the relevance of the footedness assessment.

Mansfield et al. ${ }^{9}$ did not find differences in the prevalence of perceptual disturbances, such as negligence and history of pushing, between the groups that overloaded the unaffected limb or the affected hemibody and the group with symmetrical weight-bearing distribution. Although recent studies ${ }^{9,11,12,13}$ point to the relationship between sensory deficits and asymmetry in the weight-bearing distribution during upright stance, more robust evidence must be attained.

According to the relationship between the severity of post-stroke motor deficits and the weight-bearing distribution, some evidence indicates that individuals with more severe hemiparesis tend to adopt a more asymmetric strategy when compared to those with mild hemiparesis ${ }^{6,9,11,13}$. In this regard, Mundim et al. ${ }^{7}$ have hypothesized that the lower limb predominantly used for support during an upright stance is established by preference for post-stroke hemiparesis patients presenting with mild to moderate hemiparesis, or by convenience in the patients with moderate to severe hemiparesis. In other words, the dominance would be severity-dependent and footedness must be assessed.

Given the relevance of measuring footedness, the present work proposed to adapt the WFQ-R cross-culturally and to verify the inter-rater and test/retest reliability from its measure to identify footedness for post-stroke hemiparesis and able-bodied Brazilian people.

\section{METHODS}

In order to ensure the quality of the adapted tool, we carried out a longitudinal study to translate and adapt the WFQ-R cross-culturally and test its reliability after adaptation. The essential steps to accomplish our aim were guided by the process published by Beaton et al. ${ }^{14}$ in five sequential stages: (1) translation by two translators, (2) synthesis of translations, (3) back translation by two people who have English as their native language, (4) expert committee review and (5) pretesting in order to assess the comprehension of the questionnaire.

This guideline refers to international rules established to secure the maintenance of equivalence between the original questionnaire version and the target, in this case: the Brazilian population. Once complete, the WFQ-R-Brazil was submitted to psychometric testing to verify the inter-rater and test/retest reliabilities.

Before initiating cross-cultural adaptation, the researcher Lorin Elias (University of Saskatchewan, Canada) was asked to authorize the development of the Brazilian version. This study was approved by the Local Ethics Committee, D.C. (Report 199.318/2013) and all the participants signed an informed consent form.

\section{Waterloo Footedness Questionnaire-Revised}

The WFQ-R assesses the foot preferentially used in two different situations: (1) by performing tasks with objects (e.g. kicking a ball straight towards a target or picking up a marble with the toes), and (2) stabilizing the body (e.g. standing on one leg). Items 1, 3, 5, 7 and 9 refer to task with objects, while items $2,4,6,8$ and 10 refer to body stabilization tasks ${ }^{5}$. For 
each item, respondents can answer: always the left (-2); often the left (-1); both (0); often the right (1) and always the right (2). The items are then scored from -2 to 2 , and the total score can range from -20 to 20 , according to the given answers. From the sum of the items, the footedness can be classified as: left, for scores between -20 to -7 ; mixed, for scores between -6 to 6 and right, for scores between 7 and $20^{5}$.

\section{Translation}

Initially, the items in the original version of the WFQ- R were independently translated into Brazilian Portuguese by two native Brazilian speakers who had Brazilian Portuguese as their mother tongue and were fluent in English. Only one of the translators was aware of the results analyzed by the questionnaire. The other translator had no knowledge of the concepts, being characterized as a "naive" translator. Therefore, two independent versions (T1 and T2) were produced.

\section{Synthesis}

In order to develop the first Brazilian Portuguese version of the questionnaire, the two translated versions of WFQ-R (T1 and T2) were compared and synthesized by an observer and an initial consensus was obtained. The Brazilian Portuguese language version was called the WFQ-R-Brazil.

\section{Back translation}

The first Brazilian Portuguese version of the WFQ-R (T1 and T2, WFQ-R-Brazil) was back translated into English by two professional bilingual translators who were native English speakers and fluent in Brazilian Portuguese. They did not have any knowledge about the purpose of the instrument.

Following this, the two back-translated versions were compared with the original version of the WFQ-R for validation and analysis of the translated version, to determine if it reflected the same original meaning.

\section{Expert committee review}

A committee of three bilingual rehabilitation specialists independently analyzed the semantic, idiomatic, experimental, and conceptual equivalences of the WFQ-R-Brazil ${ }^{14}$, which was considered the prefinal version for field testing. During this phase, committee members had access to the original English version, the Brazilian translation and the back-translated version in English.

Committee meetings were regularly held to find the linguistic equivalence necessary to create the prefinal version. The words judged not to be equivalent by one of the members, and text adaptations, were reviewed and discussed to reach agreement on the preliminary version applied to the Brazilian population (prefinal version).

\section{Pretesting}

The prefinal version (Appendix) of the WFQ-R-Brazil was applied to 24 participants, 12 post-stroke hemiparesis patients and 12 able-bodied individuals (hemiparesis and control groups), and the cultural equivalence was tested. The sample was formed by convenience from the database of the participants enrolled in the Community Program, located in the Federal District of Brasília, Brazil.

The inclusion criteria for the hemiparesis group were: 1 ) to have a minimum period of six months post-ischemic middle cerebral artery stroke, confirmed by computed tomography of the skull, magnetic resonance imaging or clinical signs compatible with this type of lesion $\left.{ }^{15}, 2\right)$ to have a spastic hemiparesis as a motor sequela; 3 ) to be able to stand, either using or not using an auxiliary device; 4) to sign the written informed consent form. Individuals with another neurological disease (besides the stroke that caused the hemiparesis) and/or orthopedic, cardiac, pulmonary and vestibular dysfunctions compromising the ability to perform the tests were excluded.

The able-bodied individuals in the control group, who were recruited from the community at large, were matched by gender, age, and body mass index (BMI) to obtain a sample with characteristics normalized according to the participants from the hemiparesis group. Any able-bodied individuals with neurological, orthopedic, cardiac, or pulmonary diseases, and/or vestibular dysfunctions that compromised the ability to perform the tests were excluded.

For both groups, those who: 1) reported pain during the procedures; 2) had detectable cognitive alterations on the Mini Mental State Examination (MMSE), considering cutoff points of 13 for illiterates, 18 for individuals with schooling between one and seven years, and 26 for those with schooling equal to or greater than eight years ${ }^{16,17}$, were also excluded.

The power of the test was calculated as recommended by Walter et al. ${ }^{18}$ for sample size and optimal designs for reliability studies determined after the end of the experiment. For the hemiparesis group, the power for repeated measures during inter-rater reliability was $71 \%$ considering $n=12$, significance level of $\alpha=0.05$, acceptable reliability of 0.70 , expected reliability of 0.86 and drop-out of $0 \%$. In the same group, the power was also calculated for repeated measures during test/retest reliability resulting in a power of $98 \%$ considering $\mathrm{n}=12$, significance level of $\alpha=0.05$, acceptable reliability of 0.70 , expected reliability of 0.93 and drop-out of $0 \%$.

The inter-rater reliability for the control group showed a power of $75 \%$ considering $n=12$, significance level of $\alpha=0.05$, acceptable reliability of 0.70 , expected reliability of 0.88 and drop-out of $0 \%$. In the same group, the power for repeated measures during test/retest reliability resulted in a power of $48 \%$ considering $n=12$, significance level of $\alpha=0.05$, acceptable reliability of 0.70 , expected reliability of 0.52 and drop-out of $0 \%$.

The participants were instructed by the researchers to complete the questionnaire, taking the time required, and to take notes about the difficulties in understanding the items, incomprehension of words or lack of clarity in the response options. For those participants who were illiterate or semi-literate, the questionnaire was administered by interview with a properly-trained 
examiner. After completing the questionnaire, the individuals were asked about the difficulties encountered in understanding the items and answers to the questions.

Before the reliability procedures, all participants were assessed by a physical therapist who recorded descriptive variables (quantitative and qualitative) to characterize the hemiparesis and control groups. The quantitative variables included age, body mass index (BMI), and the Mini Mental State Examination $(\mathrm{MMSE})^{19}$. The qualitative variables included were gender, activity level, smoking, alcoholism and gait assistive device users. For only the hemiparesis group, the quantitative variables also included chronicity, Stroke-Specific Quality of Life ${ }^{20}$, Canadian Occupational Performance Measure $(\mathrm{COPM})^{21}$, heminegligence and Pusher syndrome scores ${ }^{22}$.

\section{Inter-rater and test/retest reliability procedures}

The hemiparesis $(n=12)$ and control $(n=12)$ groups agreed to take part in the reliability procedures designed to take place over two days (test and one-week retest). On the first day (test), two independent raters interviewed the participants by applying the WFQ-R-Brazil one after the other, within a minimum interval of 15 minutes between them, recording the total score measured by Rater 1 and repeated by Rater 2 .

On the second day, the retest, a new interview, reapplying the WFQ-R-Brazil, was conducted by one of the two raters (Rater 1), who replicated the same steps accomplished in the test. The retest was performed one week after the test with a maximum tolerance of three days before or after one week.

\section{Variables, data processing and statistical analysis}

Descriptive statistics were applied to define the quantitative and qualitative variables. The central tendency (average) with dispersion (standard deviation) and frequency distribution, characterized both groups (hemiparesis and control).

All descriptive quantitative variables taken from both groups were expressed as a Gaussian distribution by the Shapiro-Wilks test. Therefore, the statistical inferences between the groups were determined through parametric tests. Differences were detected by the t-test for independent samples. The descriptive quantitative variables taken only from the hemiparesis group were not expressed as a Gaussian distribution by the Shapiro-Wilks test, so the statistical inferences were determined by a non-parametric test the Wilcoxon test. Frequency distributions were shown for descriptive qualitative variables, and the discrepancies between the expected proportion of the hemiparesis group and the observed proportions for the control group were analyzed with Fisher's exact test.

The main variable, the score measured by the WFQ-R-Brazil, was recorded by the two raters during the test and at the one-week retest (repeated measures). Only the repeated measures taken from the hemiparesis group was expressed as a Gaussian distribution. For this reason, the Pearson correlation test was applied for the repeated measures in the hemiparesis group while Spearman's correlation test was applied for the repeated measures in the control group. Positive correlation indexes (CI) were classified as: poor $(\mathrm{CI}<0.50)$, moderate $(0.50 \leq \mathrm{CI}<0.75)$, good $(0.75 \leq \mathrm{CI}<0.90)$ and excellent $(\mathrm{CI} \geq 0.90)^{23,24}$.

In order to evaluate the magnitude of the concordance between the repeated measures, the analysis of the limits of agreement (LOA) plotted by the Bland-Altman method was used for a $95 \%$ confidence interval. The level of significance was set at 0.05 for all statistical tests. The program used for statistical analyses was GraphPad Prism 5.

\section{RESULTS}

The results of the translation and cross-cultural adaptation process followed the same order described in the Methods, at their different stages, followed by the inter-rater and test/retest reliability procedures using repeated measures taken by the WFQ-R-Brazil.

\section{Translation and cross-cultural adaptation}

We identified a few semantic, linguistic or cultural differences during the process of the WFQ-Brazil translation and no serious discrepancies in the vocabulary. During the pretesting, all questions were appropriately answered and comprehended by all the participants.

In the review phase, by the committee of experts, some terms were replaced by others more commonly used by Brazilian Portuguese speakers to facilitate understanding, without affecting the meaning. For example, the term "insect" was replaced by "cockroach", as in Brazil, the insect most typically crushed by foot is the cockroach. The term "train tracks" was replaced by "curb", as the activity of "standing on one foot only, on the train tracks" does not represent a routinely-performed activity in our population. Therefore, we opted for "curb" because "standing on one foot only, on the curb" sounds more Brazilian and requires the same task and demands on postural control. The same occurred at the back-translation stage.

\section{Characteristics of the groups tested}

The hemiparesis group ( $\mathrm{n}=12$ ) comprised an elderly sample (defined in Brazilian age parameters as 60 years old), with weight status defined as overweight $\left(25>\mathrm{BMI}>29.9 \mathrm{~kg} / \mathrm{m}^{2}\right)$, and being predominantly female (75\%), applying the same characteristics to the control group, once it was formed, by age, BMI and gender matching (Tables 1 and 2).

Despite the hemiparesis group having reached very nearly acceptable cognitive statuses as measured by the MMSE (Table 1), a mild cognitive impairment was observed when compared with the control group. Among the variables measured exclusively in the hemiparesis group, only chronicity and COPM had values different from consulted references ${ }^{23}$. Thus, our hemiparesis group comprised people dealing with 
Table 1. Characterization of the sample submitted to the WFQ-Brazil (quantitative variables).

\begin{tabular}{|c|c|c|c|c|c|c|}
\hline \multirow{2}{*}{ Quantitative Variables (units) } & \multicolumn{3}{|c|}{ Hemiparesis $(n=12)$} & \multicolumn{3}{|c|}{ Control $(n=12)$} \\
\hline & average & \pm & SD & average & \pm & SD \\
\hline Age (years old) & 61.83 & \pm & 12.88 & 61.08 & \pm & 12.28 \\
\hline $\mathrm{BMI}\left(\mathrm{kg} / \mathrm{m}^{2}\right)$ & 27.38 & \pm & 5.42 & 27.32 & \pm & 3.76 \\
\hline MMSE (points) & $\star 22.83$ & \pm & 3.73 & 27.67 & \pm & 2.27 \\
\hline Chronicity (months) & $\star \star 95.58$ & \pm & 81.13 & \multicolumn{3}{|c|}{ not applied } \\
\hline SSQOL-Brazil (score) & 169.50 & \pm & 28.39 & \multicolumn{3}{|c|}{ not applied } \\
\hline COPM performance (score) & $\star \star \star 5.17$ & \pm & 3.78 & \multicolumn{3}{|c|}{ not applied } \\
\hline COPM satisfaction (score) & $\star \star \star 5.28$ & \pm & 3.20 & \multicolumn{3}{|c|}{ not applied } \\
\hline Heminegligence (dimensionless) & 0.51 & \pm & 0.03 & \multicolumn{3}{|c|}{ not applied } \\
\hline Pusher syndrome (score) & 0.33 & \pm & 0.48 & \multicolumn{3}{|c|}{ not applied } \\
\hline
\end{tabular}

Quantitative variables are presented as average \pm standard deviation (SD). * significant ( $p<0.05)$ differences between hemiparesis and control compared by Unpaired t test; ${ }^{*}$ significant differences of the observed average when compared to the averages in the study sample by Silva et al. ${ }^{23}$; $\star \star \star ~ s i g n i f i c a n t$ differences of the observed average when compared to the averages in the study sample by Wu et al. ${ }^{21}$. The averages compared with other studies that used one sample t test. BMI: Body Mass Index; MMSE: Mini-Mental State Examination; SSQOL: Stroke-Specific Quality of Life; COPM: Canadian Occupational Performance Measure.

Table 2. Characterization of the sample submitted to the WFQ-Brazil (qualitative variables).

\begin{tabular}{|c|c|c|}
\hline Qualitative variables & Control\% (n) & Hemiparesis \% (n) \\
\hline \multicolumn{3}{|l|}{ Gender } \\
\hline Male & $25(03)$ & $25(03)$ \\
\hline Female & $75(09)$ & $75(09)$ \\
\hline \multicolumn{3}{|l|}{ Physical activity level } \\
\hline Sedentary & $25(03)$ & $58(07)$ \\
\hline Active & $75(09)$ & $42(05)$ \\
\hline \multicolumn{3}{|l|}{ Smoking } \\
\hline Smoker & $08(01)$ & $00(00)$ \\
\hline Non-smoker & $92(11)$ & $100(12)$ \\
\hline \multicolumn{3}{|l|}{ Alcohol } \\
\hline Occasional consumption & $17(02)$ & $8(01)$ \\
\hline No consumption & $83(10)$ & $92(11)$ \\
\hline \multicolumn{3}{|l|}{ Gait assistive device* } \\
\hline User & $00(00)$ & $58(07)$ \\
\hline Not user & $100(12)$ & $42(05)$ \\
\hline
\end{tabular}

unilateral motor impairments for longer than the participants in the study by Silva et al. ${ }^{23}$ (28.50 months), had a quality of life typically found in those with a post-stroke hemiparesis (scored 179.0), with a much better perception of their performance and satisfaction measured by the COPM than the perception observed by $\mathrm{Wu}$ et al. $^{21}$, and were not diagnosed as heminegligent or a Pusher syndrome patient.

Qualitative variables recorded did not show discrepancies between proportions for activity level (sedentary vs. active), smoking and alcoholism. However, a majority of gait assistive device users was found in the hemiparesis group while no user was present in the control group (Table 2).

\section{Reliability analysis}

The analysis of the inter-rater reliability obtained for the hemiparesis group showed a good CI value (0.864, Figure B), which was increased to excellent when comparing repeated measures taken in the test/retest (0.927, Figure D). The LOA was exactly the same (from -11.50 up to 12.16) for both reliabilities (Figures B and D), with the majority of the repeated measures by raters, or presented small or no significant deviation from zero in the retest.

The same analysis for the control group also showed a good CI value (0.875, Figure A) when comparing repeated measures by raters. However, the repeated measures in the retest presented a moderate $\mathrm{CI}$ value $(0.523$, Figure $\mathrm{B})$. The LOA in the inter-rater analysis showed a very narrow range from -5.79 to 5.961 (Figure A), while in the test/retest analysis the LOA was near the limits observed in the hemiparesis group ( from -11.61 up to 10.78, Figure C). Almost all repeated measures taken by raters presented small or no significant deviations from zero (Figure A), differing from repeated measures taken between test/retest when two repeated measure were in or out the LOA (Figure C).

\section{DISCUSSION}

The cross-cultural adaptation of a questionnaire for use in a country, culture or language, different from that for which it was developed, requires a specific method to achieve equivalence between the original and translated versions ${ }^{19}$. Although widely used in research and clinical practice in different countries, the WFQ-R had not been translated or adapted to 


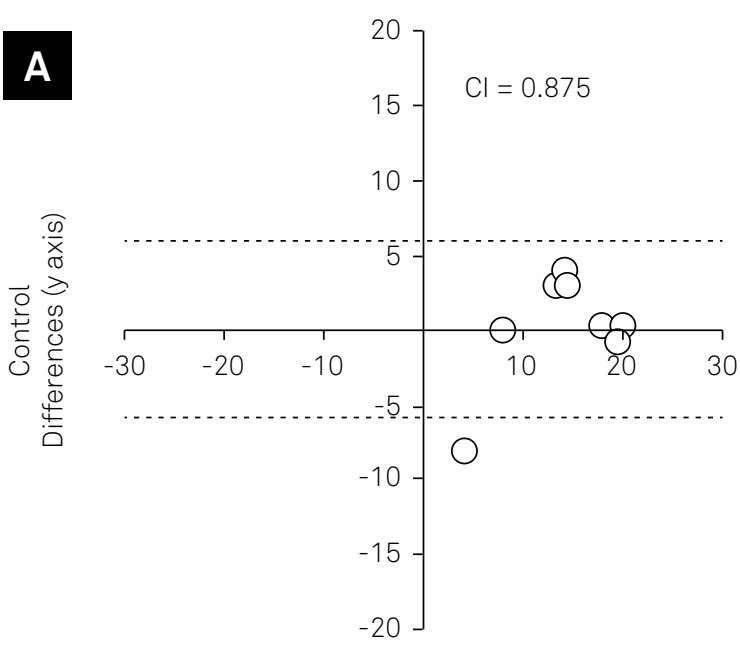

Average (x axis)

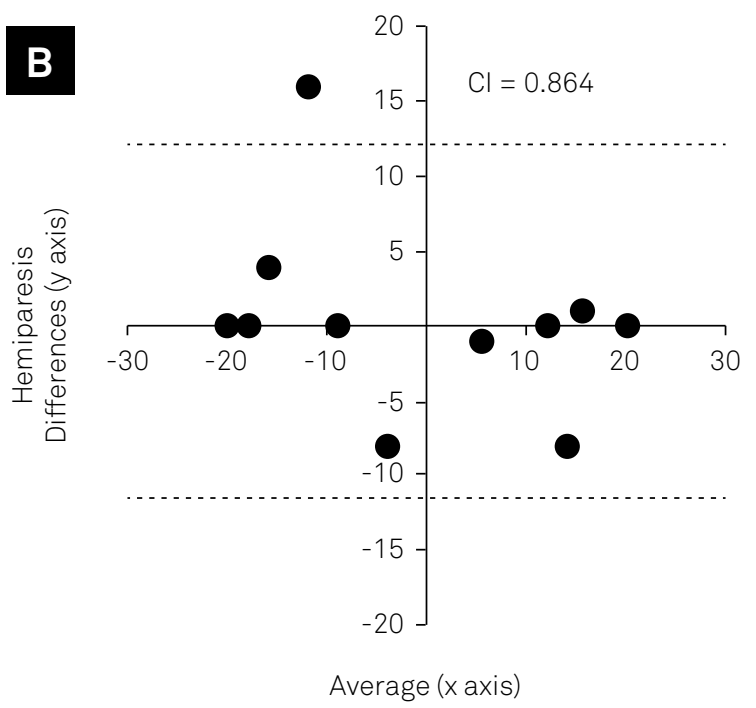

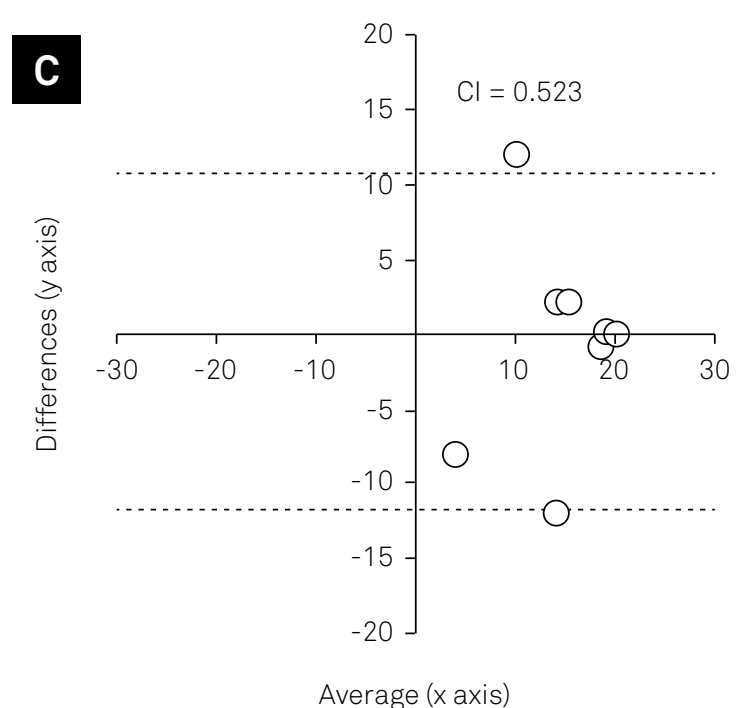

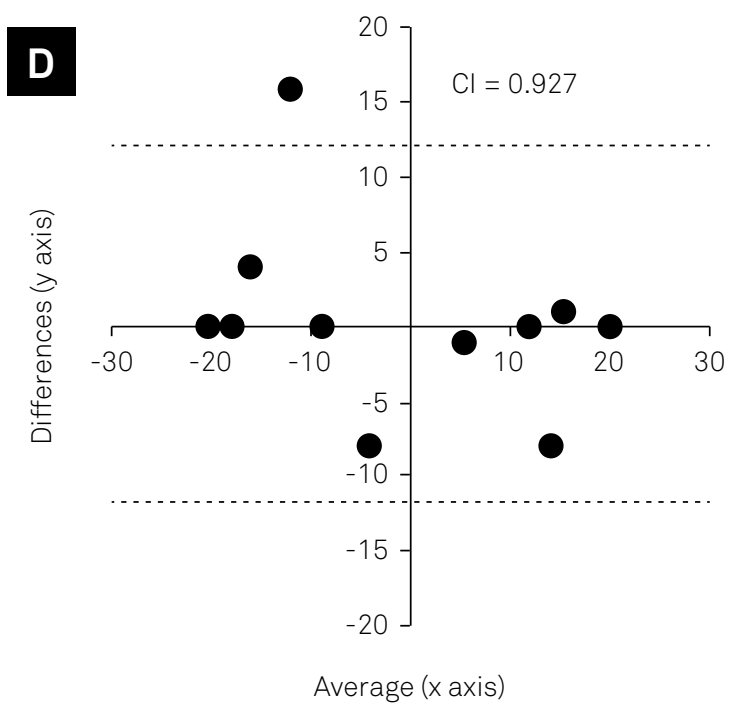

Figure. Bland-Altman plots. The plots in the left column (A and B) show the inter-rater comparison between repeated measures for control (white circles, A) and hemiparesis (black circles, B) groups. The plots in the right columns (C and D) show the test/retest comparison in the same conditions. Upper and lower dashed lines show the bounds of a 95\% range of the limit of agreement (LOA), and the continuous line indicates zero values for each graph. The correlation index (Cl) between measures obtained during each test by each rater are indicated for each graph.

Portuguese spoken in Brazil until now. According to the search carried out by our research team, only the original version (English) and a Greek version ${ }^{25}$ were available to the public.

The cross-cultural adaptation process of the WFQ-R to Brazilian Portuguese revealed some very particular adaptations during translation and back translation phases of the instrument, with no substantial differences in the essential meaning.

Notably, in the review phase by our committee of experts, some adaptations were recommended to improve understanding. For example, the term "insect" was replaced by "cockroach" as cockroaches are the most common insects that Brazilian's use their feet to crush. The term "train tracks" was replaced by "curb": the step between the sidewalk and the gutter of the pavement, as for Brazilian people, standing on one foot only on the train tracks is not a commonly-performed task in our country. The replacements represented similar meanings and task, and therefore maintained the equivalence ${ }^{19}$. The prefinal version of the WFQ-R-Brazil took no longer than five minutes to be applied, confirming its quality of being an instrument quick and easy to use.

Once the WFQ-R-Brazil was ready to apply, we conducted the reliability procedures in a sample of participants in the hemiparesis and control groups. The average age of the hemiparesis group was $61.83 \pm 12.88$ years old, similar to the average age of the participants taking part in other studies ${ }^{7,25,26}$. Considering gender, $75 \%$ of the participants with post-stroke hemiparesis 
in this study were women, against the trend observed in other research studies, in which a higher prevalence of men was found ${ }^{27,28}$. Additionally, Pereira et al. $^{28}$, in a study on the prevalence of stroke in elderly citizens from the city of Vassouras, in the municipality of Rio de Janeiro, did not observe significant differences in the ratios of men and women ${ }^{28}$.

Both our groups had acceptable cognitive statuses, assessed by the MMSE, although the participants in the hemiparesis group had lower scores. Memory, orientation, language and attention deficits are commonly reported in elderly people with a history of post-stroke hemiparesis ${ }^{28}$. Moreover, as $50 \%$ of the participants in the hemiparesis group only had schooling ranging from one to four years, the lower schooling levels could have contributed to the lower cognitive performance in this group ${ }^{23,25}$.

Our hemiparesis sample, made up of people living for a long period with their disability (20 to 254 months), may have contributed to the increased quality of life shown by the high scores in the Stroke-Specific Quality of Life-Brazil ${ }^{23,26,28}$. According to the activities identified in the COPM, the participants identified activities related to functional mobility, such as independent gait (no need for assistive device or having to be accompanied by third parties), and gait tolerance and the ability to climb/descend stairs.

The results of the inter-rater and test/retest reliability for hemiparesis and control groups did not exhibit the same repeatability behavior. Whereas for the participants with post-stroke chronic hemiparesis, the repeated measures by different raters and between tests resulted in good and excellent CI values with LOA ranging from -11.50 to 12.16 ; for the control group the repeated measures resulted in a good CI only observed in the inter-rater reliability with a narrower range of the LOA than the range calculated in the hemiparesis group. In addition, despite the LOA observed in the repeated measures during retest for the control group having maintained the same range expressed in the hemiparesis group, the CI value calculated from repeated measures between test and retest for the control group showed a moderate reliability.
Although the repeatability parameters for both groups in the different analysis (inter-rater and test/retest) have resulted in acceptable reliability for use, what could explain the differences observed in the behavior of the measurements for different groups and analysis?

An initial examination could have been suggested by focusing on the potential to change opinions about the preferred foot in the control group, which was not observed in the hemiparesis group. With exception of a single individual for whom the average of the repeated measure by raters revealed a mixed footedness (outlier in the Figure A), all the other participants from the control group showed a consistent right footedness, identified by small or no differences between the repeated measures assessed by different raters. However, in the retest, the differences between the repeated measures observed in the control group increased, but was not able to change the average, the range of variation still expressing right footedness.

On the other hand, the hemiparesis group expressed a very varied footedness - left, mixed and right - probably influenced by the unilateral impairment in the affected hemibody ${ }^{7}$, and this did not change in the retest (Figure B and D). Presumably, the post-stroke hemiparesis participants in the sample had no doubts about their preferred foot, once they had to use the non-affected hemibody predominantly. Considering that foot preference is commonly analyzed in bilateral tasks, Wang and Newell $^{29}$ stated that it may be different in unilateral tasks. Thus, they propose that the foot preference is dependent on the task and the context in which it is performed ${ }^{3,7}$, opening possibilities to changes of mind.

In conclusion, the Brazilian version of the WFQ-R-Brazil did not show semantic, linguistic or cultural discrepancies that might suggest any restriction for its use by the Brazilian population, with or without hemiparesis after stroke. Good-to-excellent reliabilities were found for the hemiparesis group and good-tomoderate reliabilities were shown by the control group, which was more susceptible to changes. Our results confirm that the WFQ-R-Brazil produced a reliable measure to be used in clinical practice and in research to identify the lower limb preferentially used in different types of tasks.

References

1. Haddad JM, Rietdyk S, Ryu JH, Seaman JM, Silver TA, Kalish JA et al. Postural asymmetries in response to holding evenly and unevenly distributed loads during self-selected stance. J Mot Behav. 2011;43(4):345-55. https://doi.org/10.1080/00222895.2011.596169

2. Mutha PK, Haaland KY, Sainburg RL. The effects of brain lateralization on motor control and adaptation. J Mot Behav. 2012;44(6):455-69. https://doi.org/10.1080/00222895.2012.747482

3. Wang Z, Newell KM. Footedness exploited as a function of postural task asymmetry. Laterality. 2013;18(3):303-18. https://doi.org/10.1080/1357650X.2012.672423

4. Sadeghi H, Allard P, Prince F, Labelle H. Symmetry and limb dominance in able-bodied gait: a review. Gait Posture. 2000;12(1):34-45. https://doi.org/10.1016/S0966-6362(00)00070-9
5. Elias LJ, Bryden MP, Bulman-Fleming MB. Footedness is a better predictor than is handedness of emotional lateralization. Neuropsychologia. 1998;36(1):37-43. https://doi.org/10.1016/S0028-3932(97)00107-3

6. Blaszczyk JW, Prince F, Raiche M, Hébert R. Effect of ageing and vision on limb load asymmetry during quiet stance. J Biomech. 2000;33(10):1243-8. https://doi.org/10.1016/S0021-9290(00)00097-X

7. Mundim AC, Paz CC, Fachin-Martins E. Could be the predominantly-used hemibody related to the weight bearing distribution modified by the chronic hemiparesis after stroke? Med Hypotheses. 2015;85(5):645-9. https://doi.org/10.1016/j.mehy.2015.08.007 
8. Hesse S, Schauer M, Jahnke MT. Standing-up in healthy subjects: symmetry of weight distribution and lateral displacement of the centre of mass as related to limb dominance. Gait Posture. 1996;4 (4):287-92. https://doi.org/10.1016/0966-6362(95)01051-3

9. Mansfield A, Danells CJ, Zettel JL, Black SE, Mcllroy WE. Determinants and consequences for standing balance of spontaneous weight-bearing on the paretic side among individuals with chronic stroke. Gait Posture. 2013;38(3):428-32. https://doi.org/10.1016/j.gaitpost.2013.01.005

10. Barra J, Oujamaa L, Chauvineau V, Rougier P, Pérennou D. Asymmetric standing posture after stroke is related to a biased egocentric coordinate system. Neurology. 2009;72(18):1582-7. https://doi.org/10.1212/WNL.0b013e3181a4123a

11. Tasseel-Ponche S, Yelnik AP, Bonan IV. Motor strategies of postural control after hemispheric stroke. Neurophysiol Clin.2015;45(4-5):327-33. https://doi.org/10.1016/j.neucli.2015.09.003

12. Chu VW, Hornby TG, Schmit BD. Perception of lower extremity loads in stroke survivors. Clin Neurophysiol.2015;126(2):372-81. https://doi.org/10.1016/j.clinph.2014.06.047

13. Hendrickson J, Patterson KK, Inness EL, Mcllroy WE, Mansfield A. Relationship between asymmetry of quiet standing balance control and walking post-stroke. Gait Posture. 2014;39(1):177-81. https://doi.org/10.1016/j.gaitpost.2013.06.022

14. Beaton DE, Bombardier C, Guillemin F, Ferraz MB. Guidelines for the process of cross-cultural adaptation of self-report measures. Spine. 2000;25(24):3186-91. https://doi.org/10.1097/00007632-200012150-00014

15. Teasell RW, Foley NC, Bhogal SK, Speechley MR. An evidence-based review of stroke rehabilitation. Top Stroke Rehabil. 2003;10 (1):29-58. https://doi.org/10.1310/8YNA-1YHK-YMHB-XTE1

16. Folstein MF, Folstein SE, McHugh PR. "Mini-mental state": a practical method for grading the cognitive state of patients for the clinician. J Psychiatr Res. 1975;12(3):189-98. https://doi.org/10.1016/0022-3956(75)90026-6

17. Bertolucci PH, Brucki SM, Campacci SR, Juliano Y. [The Mini-Mental State Examination in a general population: impact of educational status]. Arq Neuropsiquiatr. 1994;52(1):1-7. Portuguese. https://doi.org/10.1590/S0004-282X1994000100001

18. Walter SD, Eliaszwin M, Donner A. Sample size and optimal designs for reliability. Statistics in Medicine.1998;17(1):101-110. https://doi.org/10.1002/(SICI)1097-0258(19980115)17:1<101::AIDSIM727>3.0.CO;2-E
19. Nardone A, Godi M, Grasso M, Guglielmetti S, Schieppati M. Stabilometry is a predictor of gait performance in chronic hemiparetic stroke patients. Gait Posture. 2009;30(1):5-10. https://doi.org/10.1016/j.gaitpost.2009.02.006

20. Martin WL, Porac C. Patterns of handedness and footedness in switched and nonswitched Brazilian left-handers: cultural effects on the development of lateral preferences. Dev Neuropsychol. 2007;31(2):159-79. https://doi.org/10.1080/87565640701190734

21. Wu AJ, Radel J, Hanna-Pladdy B. Improved function after combined physical and mental practice after stroke: a case of hemiparesis and apraxia. Am J Occup Ther. 2011;65(2):161-8. https://doi.org/10.5014/ajot.2011.000786

22. Karnath $\mathrm{HO}$, Broetz D. Understanding and treating "pusher syndrome". Phys Ther. 2003;83(12):1119-25.

23. Silva FC, Silva DF, Mesquita-Ferrari RA, Fernandes KP, Bussadori SK. Correlation between upper limb function and oral health impact in stroke survivors. J Phys Ther Sci. 2015;27(7):2065-8. https://doi.org/10.1589/jpts.27.2065

24. Kapreli E, Athanasopoulos S, Stavridis I, Billis E, Strimpakos N. Waterloo Footedness Questionnaire (WFQ-R): cross-cultural adaptation and psychometric properties of Greek version. Physiotherapy. 2015;101(Suppl 1):e721. https://doi.org/10.1016/j.physio.2015.03.3577

25. Dickstein R, Nissan M, Pillar T, Scheer D. Foot-ground pressure pattern of standing hemiplegic patients: major characteristics and patterns of improvement. Phys Ther. 1984;64(1):19-23. https://doi.org/10.1093/ptj/64.1.19

26. Lu RR, Li F, Wu Y, Hu YS, Xu XL, Zou RL et al. Demonstration of posturographic parameters fo squat-stand activity in hemiparetic patients on a new multi-utility balance assessing and training system. J Neuroeng Rehabil. 2013;10(1):37. https://doi.org/10.1186/1743-0003-10-37

27. Chagas EF, Tavares MC. [Symetric and weight-transfer of hemiplegic: its relation with performance in hemiplegics functional activities]. Rev Fisioter Univ São Paulo. 2001;8(1):40-50. Portuguese. https://doi.org/10.1590/fpusp.v8i1.79397

28. Pereira LC, Botelho AC, Martins EF. Relationships between body symmetry during weight-bearing and functional reach among chronic hemiparetic patients. Rev Bras Fisioter. 2010; 14(3):229-66. https://doi.org/10.1590/S1413-35552010000300009

29. Wang Z, Newell KM. Asymmetry of foot position and weight distribution channels the inter-leg coordination dynamics of standing. Exp Brain Res. 2012;222(4):333-44. https://doi.org/10.1007/s00221-012-3212-7 


\section{APPENDIX}

\section{Questionário de Predominância de Uso de um Pé de Waterloo Revisado}

Versão em Português falado no Brasil

\section{Instruções:}

Por gentileza, responda cada uma das questões a seguir de maneira a mais bem descrever suas habilidades. Se você SEMPRE usa um pé para desempenhar as atividades descritas abaixo, circule DS ou ES (para Direita Sempre ou Esquerda Sempre). Se você FREQUENTEMENTE usa um pé, circule DF ou EF (para Direito Frequentemente ou Esquerdo Frequentemente), se for apropriado. Se você usa AMBOS os pés com a mesma frequência, circule AMB.

Por favor, não marque a mesma resposta para todas as questões. A cada questão, imagine você mesmo desempenhando cada atividade e, somente então, marque a resposta apropriada. Se necessário, pare e simule o movimento para descobrir a sua forma de uso.

\begin{tabular}{|c|c|c|c|c|c|}
\hline 1.Qual pé você usaria para chutar uma bola parada em linha reta em direção a um alvo a sua frente? & DS & DF & AMB & ES & EF \\
\hline 2. Se você tivesse que ficar em um pé só sem ajuda, em qual pé ficaria? & DS & DF & AMB & ES & $\mathrm{EF}$ \\
\hline 3. Qual pé você usaria para alisar a areia da praia? & DS & DF & AMB & ES & EF \\
\hline 4. Se você tivesse que subir em uma cadeira, qual pé você colocaria primeiro sobre ela? & DS & DF & AMB & ES & EF \\
\hline 5. Qual pé você usaria para esmagar uma barata agitada se movendo no chão? & DS & DF & AMB & ES & $\mathrm{EF}$ \\
\hline 6. Se você tivesse que se equilibrar em um pé só sobre o meio-fio da calçada, qual pé usaria? & DS & DF & AMB & ES & EF \\
\hline 7. Se você tivesse que pegar uma bolinha de gude usando os dedos do pé, qual pé usaria? & DS & DF & AMB & ES & EF \\
\hline 8. Se você tivesse que pular em um pé só, qual pé usaria? & DS & DF & AMB & ES & EF \\
\hline 9. Qual pé você usaria para cravar uma pá na terra? & DS & DF & $\mathrm{AMB}$ & ES & EF \\
\hline $\begin{array}{l}\text { 10. Posicionado confortavelmente em pé, pessoas inicialmente colocam a maioria do seu peso sobre } \\
\text { um dos pés, dobrando levemente o joelho da outra perna. Qual pé você colocaria a maior parte do } \\
\text { seu peso primeiro? }\end{array}$ & DS & DF & AMB & ES & EF \\
\hline $\begin{array}{l}\text { 11. Existe alguma razão (ou seja, lesão/desconforto) para que você tenha mudado o seu pé preferido } \\
\text { para qualquer uma das atividades acima? }\end{array}$ & \multicolumn{5}{|c|}{ ( ) Sim ( ) Não } \\
\hline $\begin{array}{l}\text { 12. Você têm dado treinamento especial ou preferência de uso para um pé em particular para certas } \\
\text { atividades? }\end{array}$ & \multicolumn{5}{|c|}{ ( ) $\operatorname{Sim}($ ) Não } \\
\hline
\end{tabular}

